\title{
Analysis on borehole stability of gas drilling with complete stress-strain and thermal stress theory
}

\author{
Zhongxi Zhu' ${ }^{1} \cdot$ Chaofei Wang ${ }^{2} \cdot$ Chao Xiong $^{3} \cdot$ Wanneng Lei ${ }^{4}$
}

Received: 20 January 2021 / Accepted: 8 November 2021 / Published online: 4 February 2022

(c) The Author(s) 2022

\begin{abstract}
In conventional mud drilling, sufficient drilling fluid density is required to maintain wellbore stability. However, in gas drilling, the support ability of gas in wellbore is very weak, and the wellbore stability is usually good. This shows that the borehole instability mechanism of gas drilling is different from that of mud drilling. In gas drilling, the borehole wall rock still has a certain bearing capacity after reaching the peak strength. In this paper, the stability of gas drilling wellbore is studied by using the complete stress-strain model. The deformation of rock around borehole in gas drilling can be divided into elastic zone, plastic zone, and broken zone. The radii of plastic zone and broken zone were used to evaluate the stability of borehole wall. This method has a good general applicability to the case of no thermal stress in borehole wall rock. However, due to throttling and cooling as gas flows out of the bit nozzle during gas drilling, thermal stress occurs when the cryogenic flow in the annulus meets the hot formation. Therefore, thermal stress is introduced into the complete stress-strain calculation model. The radii of plastic zone and broken zone are calculated according to the actual drilling data, and compared with the measured borehole diameter. The results show that the model is reasonable and effective. Analysis shows that in gas drilling process, the borehole temperature is much lower than the original formation temperature near the bottom of the borehole, and the borehole temperature is higher than the formation temperature in the upper part of the borehole. Thermal stress has a significant effect on borehole stability. The thermal stress in the bottom borehole makes the rock shrink and offset the expansion of the original in situ stress on the surrounding rock, thus enhancing the stability of the borehole wall. The surrounding rock in the top borehole expands under the action of thermal stress, enhancing the expansion of the surrounding rock toward the borehole and aggravating the instability of the borehole wall. The model can be used to better explain the wellbore instability mechanism of gas drilling, and it is more intuitive to use plastic zone radius and broken zone to characterize wellbore stability of gas drilling.
\end{abstract}

Keywords Complete stress-strain theory $\cdot$ Thermal stress $\cdot$ Gas drilling $\cdot$ Strength $\cdot$ Elastic-plastic softening

\section{Introduction}

Responsible Editor: Santanu Banerjee

Zhongxi Zhu

zhuzhongxi@yangtzeu.edu.cn

1 National Engineering Laboratory of Petroleum Drilling Technology, Leak Resistance \& Sealing Technology Research Department, Yangtze University, Wuhan 430100, China

2 Engineering Technology Department of PetroChina Xinjiang Oilfield Company, Karamay 834000, China

3 Engineering Technology Research Institute of PetroChina Xinjiang Oilfield Company, Karamay 834000, China

4 Production Capacity Construction Division, Tarim Oilfield Company, Korla 841000, China
Gas drilling technology can improve rate of penetration, avoid lost circulation, and overcome sensitivity of formation water. The gas in the borehole is not enough weight to support the wall of borehole, and the borehole will inevitably deform because of the original in situ stress. However, in many gas drilling processes, no serious wellbore instability occurred. The theory of stability by using drilling fluid to prop up the borehole wall does not explain this phenomenon well. Generally, researchers regard rock as elastic material when analyzing the stability of borehole wall, and believe that rock failure will occur when the stress exceeds the peak strength, and use it as the limiting condition for studying the stability of borehole wall to calculate and estimate the 
collapse pressure of borehole wall. Rocks can not only bear the load before failure, but also has a certain load capacity after failure. The complete stress-strain process of rocks can more actually reflect the yield procedure and deformation characteristics of rocks.

However, the complete stress-strain model of rock is too complex to analyze the engineering problems (Yuan and Chen 1986; Chen and Yuan 1988). The estimation methods of collapse pressure is based on the hypothesis that the rock completely loses its bearing capacity after reaching the peak strength and compares the geostress around borehole with the rock strength (Wu and Lin 1987). Based on the air drilling practice in Karamay oilfield, it is put forward that the influencing factors of wellbore stability in air drilling include mechanics and chemistry (Li 1994). The concentration and chemical properties of liquid phase in mist drilling effected on borehole stability were evaluated by laboratory experiments (Huang et al. 1995). The von Mises failure criterion is used to get reliable prediction of the collapse pressure (Guo and Ghalambor 2002). A method for calculating collapse pressure of gas drilling wall is established on the base of rock elasticity theory and Mohr-Coulomb criterion (Jiang et al. 2007). The elastic-brittle-plastic constitutive model was established to analyze the stability of hard rock under high geostresses (Chen and Feng 2007). The failure modes of the deep rock mass contain brittle failure or ductile failure that depends on the property of rock mass and the geostress state (Zhou et al. 2008). The influence factor of pore pressure is studied during gas drilling in high-pressure gas zone, and the theory of rock elasticity is still used to calculate the collapse pressure (Liu et al. 2010). Triaxial compression test data of five different rocks were used to verify the unified strength criterion with four parameters ( $\mathrm{Lu}$ and Du 2013). Rock anisotropy effected on rock strength and collapse pressure was investigated through the modified Mogi-Coulomb criterion (Yang et al. 2020). Hydraulic fracturing practices also show that the rock around borehole still maintains stability and load capacity even if it has reached the peak strength (Ding et al. 2018).

At the same time, the gas flow in the borehole temperature and pressure changes are more complex for the compressibility of gas. Ramey presented an approximate solution to the wellbore heat-transmission problem involved in injection of hot or cold fluids (Ramey 1962). The expansion factor in the yield zone and the cohesive effect of broken material is considered to develop around the excavation with an elastic zone beyond (Wilson 1980). A mathematical model was developed to evaluate wellbore heat losses and two-phase pressure drop in concentric-pipe steam injection wells (Griston and Willhite 1987). Generalized analytical models were presented to compute circulating fluid temperature in conduits for both forward- and reverse-circulation cases, as a function of circulation time and well depth (Hasan et al. 1996a, b). The difference temperature between drilling fluid and borehole wall and the thermal stress in rock around the borehole were studied (Nguyen et al. 2010; Zhang et al. 2012). Akong et al. investigated the effect of temperature on wellbore stability under thermal effects at the wellbore wall during mud drilling (Akong et al. 2011). The temperature drop of gas flow is larger than liquid flow in the borehole, especially near the bottom of hole; the temperature on the wall of borehole is lower than geothermal value ( $\mathrm{Li}$ et al. 2015; Guo et al. 2016). Therefore, the thermal stress of the borehole should be taken into account when the stresses around the borehole are analyzed in gas drilling.

The rock around borehole will be deformed by original in situ stress because the gas pressure in the borehole during gas drilling is too low to support the borehole wall. According to the complete stress-strain model of rock, the borehole stability is analyzed. Furthermore, the phenomenon of throttling and cooling is easy to occur near the bottom of the borehole during gas drilling, and thermal stress will be generated at the borehole wall, which will also have a certain influence on the stability of the borehole wall. Therefore, a thermo-elastoplastic model is established to analyze the wellbore stability of gas drilling.

\section{Mathematic model}

\section{Ideal elastic-plastic softening model for rocks}

The curve of the complete stress-strain relation of rock (Fig. 1A) is simplified into the simplest broken line (Fig. 1B). The $a-c-f$ broken line in Fig. 1B represents an ideal elastic-plastic softening model. The simplified model divides the deformation process of rock into three stages: elastic deformation, plastic softening deformation, and residual deformation (Yuan and Chen 1986). The elastic modulus of elastic deformation is $E$, and the softening modulus of plastic softening deformation is $E_{p}$, so the fragility coefficient is $\beta=E_{p} / E$ (Guo et al. 2021; Li et al. 2017).

\section{Strength of rock in the elastic deformation stage}

Most rocks follow the Hooke's law in the stage of elastic deformation and meet the Mohr-Coulomb criterion (Yang et al. 2019; AL-AJMI and ZIMME 2005, 2006) at the yield of elastic deformation; the strength function is expressed as follows: 
Fig. 1 The complete stressstrain relationship of rocks. A Complete stress-strain curve. B Ideal elastic-plastic softening model

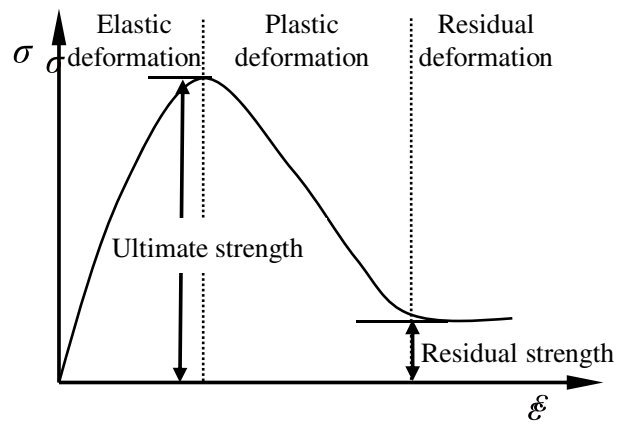

(A)

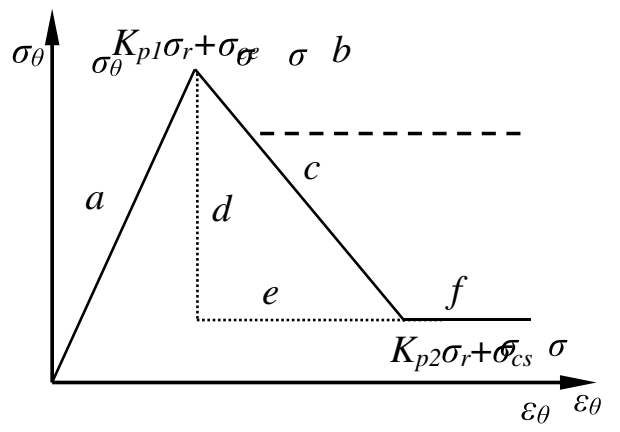

(B)
$\sigma_{\theta}=K_{p 1} \sigma_{r}+\sigma_{c e}$

$K_{p 1}=\frac{1+\sin \phi_{\mathrm{e}}}{1-\sin \phi_{e}}$

where $\sigma_{\theta}$ and $\sigma_{r}$ are the tangential and radial stresses, MPa; $\sigma_{c e}$ is the uniaxial compressive strength in the process of elastic deformation, $\mathrm{MPa} ; \varphi_{e}$ is the angle of internal friction of elastic deformation, degree.

\section{Strength of rock in the plastic deformation stage}

The rock strength attenuated with the development of deformation mainly because of the change of cohesion, and the strength of the plastic deformation is illustrated as follows:

$\sigma_{\theta}=K_{p 2} \sigma_{r}+\sigma_{\mathrm{cp}}$

$K_{p 2}=\frac{1+\sin \phi_{\mathrm{p}}}{1-\sin \phi_{\mathrm{p}}}$

where $\sigma_{c p}$ is the uniaxial compressive strength of the plastic deformation, MPa; $\varphi_{p}$ is the angle of internal friction of plastic deformation, degree.

\section{Strength of rock in the residual deformation stage}

The strength of the rock drops to the minimum value in the residual deformation. The strength of the residual deformation is expressed as follows:

$\sigma_{\theta}=K_{p 2} \sigma_{r}+\sigma_{\mathrm{cs}}$

where $\sigma_{c s}$ is the uniaxial compressive strength of the residual deformation, $\mathrm{MPa}$.

\section{The original in situ stresses around borehole}

It is assumed that the rock is an isotropic and homogeneous continuous medium, and the hole is in a state of plane strain under the average horizontal stress, $\sigma_{o}$. The equilibrium equation of stresses (Fang and Wang 1991) is

$r \frac{\partial \sigma_{r}}{\partial r}+\sigma_{r}-\sigma_{\theta}=0$

With the average horizontal stress increasing, the rock around the borehole divides into three regions (Fig. 2):

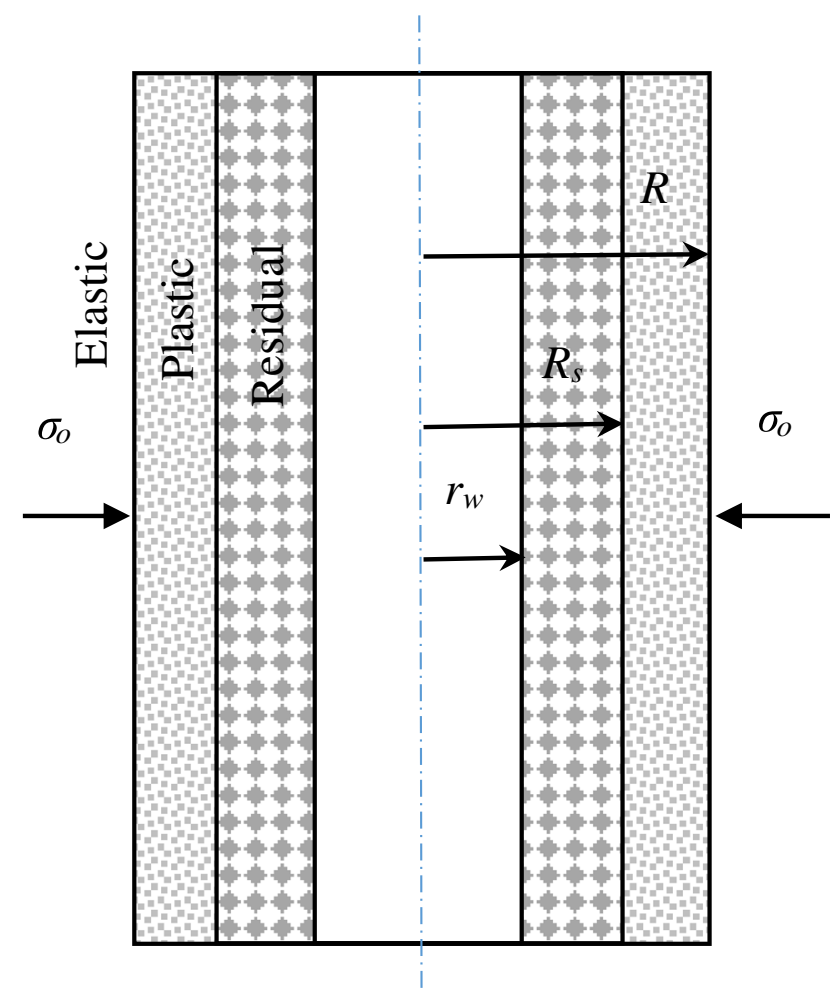

Fig. 2 Rock deformation zones around borehole 
elastic zone, plastic zone, and residual zone. If the average horizontal stress is weak, the elastic zone appears possibly only. Otherwise, the average horizontal stress is huge, and three zones appear inevitably.

$\sigma_{\mathrm{r}}=\left(\frac{2 \sigma_{\mathrm{o}}-\sigma_{\mathrm{ce}}}{k_{p 1}+1}+\frac{2 \beta M}{k_{p 2}^{2}-1}+\frac{\sigma_{\mathrm{ce}}}{k_{p 2}-1}\right)\left(\frac{r}{R_{p}}\right)^{k_{p 2}-1}-\frac{2\left(\sigma_{\mathrm{ce}}+\beta M\right)}{k_{p 2}^{2}-1}+\frac{\sigma_{\mathrm{cp}}}{k_{p 2}+1}$

1. Stresses in the elastic zone

According to the elasticity theory, the stresses in the elastic zone are:

$\sigma_{\mathrm{r}}=\sigma_{\mathrm{o}}-\left(\sigma_{\mathrm{o}}-\sigma_{\mathrm{re}}\right)\left(\frac{R_{\mathrm{p}}}{r}\right)^{2}$

$\sigma_{\theta}=\sigma_{\mathrm{o}}+\left(\sigma_{\mathrm{o}}-\sigma_{\mathrm{re}}\right)\left(\frac{R_{\mathrm{p}}}{r}\right)^{2}$

In the elastic zone, the stresses inside the rock satisfy the Hooke's law, and the radial stress expression at the interface of the elastic-plastic zone can be obtained by application of the Mohr-Coulomb strength criterion:

$\sigma_{\mathrm{re}}=\frac{2 \sigma_{\mathrm{o}}-\sigma_{\mathrm{ce}}}{k_{\mathrm{p} 1}+1}$

where $R_{p}$ is the radius of the plastic zone, $\mathrm{m} ; \sigma_{o}$ is the average horizontal geostress, $\mathrm{MPa} ; \sigma_{r e}$ is the radial stress at the interface of the elastic-plastic zone, $\mathrm{MPa}$.

\section{Stresses in the plastic zone}

Due to the relative sliding inside the rock during the plastic deformation stage, the strength of the rock shows a decreasing trend. The strength attenuation law of the plastic zone in Eq. (3) can be expressed as follows:

$\sigma_{\mathrm{cp}}=\sigma_{\mathrm{ce}}-\beta M\left[\left(\frac{R_{\mathrm{p}}}{r}\right)^{2}-1\right]$

Although the rock strength is lower than the peak strength at the stage of plastic deformation, there is still certain elastic deformation energy inside the rock, which is defined as the plastic deformation modulus. The plastic deformation modulus is defined as follows:

$M=\frac{(1+v)\left[\left(k_{p 1}-1\right) \sigma_{\mathrm{o}}+\sigma_{\mathrm{ce}}\right]}{k_{p 1}+1}$

where $M$ is the plastic deformation modulus, $\mathrm{MPa} ; \beta$ is the fragility coefficient; $\nu$ is Rock Poisson's ratio.

$$
\sigma_{\theta}=k_{p 2} \sigma_{\mathrm{r}}+\sigma_{\mathrm{cp}}
$$

$\sigma_{\theta}=k_{p 2} \sigma_{\mathrm{r}}+\sigma_{c s}$
The radial stress is continuous at the junction of elastoplastic zones, so when $r=R_{p}, \sigma_{r}=\sigma_{r e}$, the stresses in the plastic zone can be illustrated as follows:

3. Stresses in the residual zone

At the junction of the plastic zone and the broken zone, when $r=R_{s}=\lambda R_{p}, \sigma_{c p=} \sigma_{c s}$. Equation (10) changes as follows:

$\sigma_{\mathrm{cs}}=\sigma_{\mathrm{ce}}+\beta M\left[1-\frac{1}{\lambda^{2}}\right]$

$\lambda=\sqrt{\frac{\beta M}{\sigma_{\mathrm{ce}}-\sigma_{\mathrm{cs}}+\beta M}}$

where $R_{s}$ is the radius of the broken zone, $\mathrm{m} ; \lambda$ is the radius ratio of the broken zone to the plastic zone, and $\lambda=R_{s} / R_{p}$.

The residual strength expressed in Eqs. (14) and (5) is substituted into the equilibrium Eq. (6) and integrated, and the residual stresses can be obtained by combining the boundary conditions. The radial stress at the junction of the plastic zone and the residual zone is continuous, so the radial stress obtained by substituting $r=R_{s}$ into Eq. (12) is taken as the boundary condition:

$$
\begin{gathered}
\sigma_{r}=\left(\frac{2 \sigma_{\mathrm{o}}-\sigma_{c e}}{k_{p 1}+1}+\frac{\sigma_{c e}+\beta M}{k_{p 2}-1}-\frac{\beta M}{k_{p 2}+1}\right)\left(\frac{r}{R_{p}}\right)^{k_{p 2}-1}+ \\
\left(\frac{\beta M}{k_{p 2}+1} \frac{1}{\lambda^{2}}+\frac{\sigma_{c s}-\sigma_{c e}-\beta M}{k_{p 2}-1}\right)\left(\frac{r}{\lambda R_{p}}\right)^{k_{p 2}-1}-\frac{\sigma_{c s}}{k_{p 2}-1}
\end{gathered}
$$

\section{Thermal stress around the borehole}

In gas drilling, the heat transfer in the borehole is regarded as steady-state heat transfer, while the heat transfer in the formation outside the borehole is considered as unsteady-state heat transfer. Mathematical models of gas flow in drillstrings and annulus can be expressed by conservation equations of mass, momentum, and energy (Hasan et al. 1996a,b; Kabir et al. 1996; Keller et al. 1973; Lee 1982): 
$\rho_{g} V_{p} A_{p} c_{p g} \frac{\partial T_{p}(z, t)}{\partial z}+2 \pi r_{p} U_{t}\left[T_{p}(z, t)-T_{A}(z, t)\right]=\rho_{g} V_{p} A_{p} c_{p g} \frac{\partial T_{p}(z, t)}{\partial t}$

$\rho_{g} V_{A} A_{A} c_{p g} \frac{\partial T_{A}(z, t)}{\partial z}+2 \pi r_{p} U_{t}\left[T_{p}(z, t)-T_{A}(z, t)\right]+$

$\pi r_{w} h_{t}\left[T_{w}(z, t)-T_{A}(z, t)\right]=\rho_{g} V_{A} A_{A} c_{p g} \frac{\partial T_{A}(z, t)}{\partial t}$

$\frac{\partial T_{w}(z, t)}{\partial t}=\frac{k_{f}}{\rho_{f} c_{p f}} \frac{1}{r} \frac{\partial}{\partial r}\left[r \frac{\partial T_{w}(z, t)}{\partial r}\right]$

where $\rho_{g}$ and $\rho_{f}$ are the density of gas and rock, $\mathrm{kg} / \mathrm{m}^{3} ; V_{p}$ and $V_{A}$ are the gas velocity in drillstrings and annulus, $\mathrm{m} / \mathrm{s}$; $A_{p}$ and $A_{A}$ are the cross-section of drillstrings and annular, $\mathrm{m}^{2} ; c_{p g}$ and $c_{p f}$ are the specific heat of gas and rock, $\mathrm{J} / \mathrm{kg}{ }^{\circ} \mathrm{C}$; $T_{p}, T_{A}$, and $T_{w}$ are the temperature of gas in drillstrings, gas in annulus, and rock in the borehole wall, ${ }^{\circ} \mathrm{C} ; U_{t}$ is the total heat transfer coefficient between the drillstrings and the rock in the borehole wall, $\mathrm{J} / \mathrm{s}{ }^{\circ} \mathrm{C} \mathrm{m} ; h_{t}$ is the heat transfer coefficient of rock in borehole wall, $\mathrm{J} / \mathrm{s}{ }^{\circ} \mathrm{C} \mathrm{m} ; k_{f}$ is the formation thermal conductivity, $\mathrm{J} / \mathrm{h}{ }^{\circ} \mathrm{C} \mathrm{m} ; r, r_{p}$, and $r_{w}$ are the radial coordinates, drillstrings radius, and borehole radius, $\mathrm{m}$; $t$ is time, $\mathrm{s} ; z$ is the well depth, $\mathrm{m}$.

When gas is circulating in the gas drilling, the temperature around the borehole is changing and an additional thermal stress field is creating. The additional thermal stress around the borehole caused by the temperature difference can be obtained according to the heat conduction theory and thermoplastics mechanics (Nguyen et al. 2010).

$$
\begin{aligned}
& \sigma_{r}^{T}=-\frac{\alpha E}{(1-v)} \frac{1}{r^{2}} \int_{r_{w}}^{r} T^{f}(r, t) r d r-\alpha E T_{w}(t) \frac{r_{w}^{2}}{r^{2}} \\
& \sigma_{\theta}^{T}=\frac{\alpha E}{(1-v)}\left[\frac{1}{r^{2}} \int_{r_{w}}^{r} T^{f}(r, t) r d r-T^{f}(r, t)\right]+\alpha E T_{w}(t) \frac{r_{w}^{2}}{r^{2}}
\end{aligned}
$$

where $\sigma_{r}{ }^{T}$ and $\sigma_{\theta}{ }^{T}$ are the thermal stresses in the radial, tangential, and axial directions caused by formation temperature changes, $\mathrm{MPa} ; \alpha$ is the thermal expansion coefficient of formation, $1 /{ }^{\circ} \mathrm{C} ; T^{f}(r, t)=T(r, t)-T_{0}, T_{w}(t)=T\left(r_{w}, t\right)-T\left(r_{w}, 0\right)$ is the temperature distribution function of formation around borehole, $T_{w}$ is the gas temperature at the borehole wall, ${ }^{\circ} \mathrm{C}$. $T_{0}$ is the initial formation temperature, ${ }^{\circ} \mathrm{C}$.

\section{The radii of plastic zone and residual zone}

1. The radius of plastic zone
In gas drilling, both the original in situ stresses and thermal stress affect the surrounding rock deformation. It is the critical state that the plastic deformation is just complete, and the residual deformation does not occur yet. The radius of plastic zone at the critical state is $R_{p c}$. The boundary conditions are $r=r_{w}, \sigma_{c e}=\sigma_{c s}, \sigma_{r}=p_{i}$. Equation (10) is substituted into Eq. (12) and combined with Eq. (21), and the radius of plastic zone can be obtained as follows:

$R_{p c}=r_{w}\left(\frac{\frac{2 \sigma_{0}-\sigma_{c e}}{k_{p 1}+1}+\frac{2 \beta M}{k_{p 2}^{2}-1}+\frac{\sigma_{c p}}{k_{p 2}-1}}{p_{i}+\frac{2\left(\sigma_{c e}+\beta M\right)}{k_{p 2}^{2}-1}+\frac{\sigma_{c p}}{k_{p 2}+1}+\alpha E T_{w}(t)}\right)^{\frac{1}{k_{p 2}-1}}$

where $R_{p c}$ is the critical radius of plastic zone, $\mathrm{m} ; p_{i}$ is the gas pressure in borehole, MPa.

The radius of residual zone at the critical state is the borehole radius. The ratio of the residual and plastic zone is defined as $\lambda=R_{s} / R_{p}$, then $\lambda=r_{w} / R_{p c}$, or $R_{p c}=r_{w} / \lambda$ at the critical state. When the rock deformation around the borehole does not stop after it reaches the critical plastic zone, the residual zone will appear. The radius of residual zone will be greater than the borehole radius, that is, $R_{s} \geq r_{w}$, or $R_{p c} \geq r_{w} / \lambda$. Therefore, comparison of the values of $R_{p c}$ and $r_{w} / \lambda$ can determine which stage of deformation appears in the surrounding borehole rock. Equation (11) can be expressed as follows according to the boundary condition: $r=r_{w}$ and $\sigma_{r}=p_{i}$.

$$
\begin{aligned}
& \left(\frac{2 \sigma_{\mathrm{o}}-\sigma_{c e}}{k_{p 1}+1}+\frac{2 \beta M}{k_{p 2}^{2}-1}+\frac{\sigma_{c e}}{k_{p 2}-1}\right)\left(\frac{r_{w}}{R_{p}}\right)^{k_{p 2}-1} \\
& -\frac{\sigma_{c e}+\beta M}{k_{p 2}-1}+\frac{\beta M}{k_{p 2}+1}\left(\frac{R_{p}}{r_{w}}\right)^{2}-p_{i}-\alpha E T_{w}(t)=0
\end{aligned}
$$

In the range of $R_{p c} \leq R_{p} \leq r_{w} / \lambda$, the radius of the plastic zone before the critical state can be gotten by the iterative solution of Eq. (24).

\section{The radius of residual zone}

When the rock around borehole reaches complete plastic deformation, the residual zone occurs, and its radius is greater than the borehole radius. The radius of residual zone can be illustrated by substituting the boundary condition of $r=r_{w}$ and $\sigma_{r}=p_{i}$ into Eq. (16).

$R_{p}=r_{w}\left(\frac{\frac{2 \sigma_{0}-\sigma_{c e}}{k_{p 1}+1}+\frac{\sigma_{c s}+\left(\sigma_{c e}+\beta M\right)\left(1-\lambda^{k_{p 2}-1}\right)}{\left(k_{p 2}-1\right) \lambda^{k_{p 2}-1}}+\frac{\beta M\left(1-\lambda^{k_{p 2}+1}\right)}{\left(k_{p 2}+1\right) \lambda^{k_{p 2}+1}}}{p_{i}+\frac{\sigma_{c s}}{k_{p 2}-1}+\alpha E T_{w}(t)}\right)^{\frac{1}{k_{p 2}-1}}$ 


$$
R_{\mathrm{s}}=\lambda R_{p}
$$

\section{The universality of the model}

The ideal elastic-plastic softening model can simplify two extreme cases: the ideal elastic-plastic model $(a-b$ line in Fig. 1B) and the ideal fragility model ( $a-d-e$ line in Fig. 1B). Kastner's formula of plastic zone radius is expressed according to the ideal elastic-plastic model. Airy's formula for the radius of plastic zone is the extreme case according to the ideal fragility model.

1. The radius of plastic zone with the ideal elastic-plastic model

When the surrounding rock conforms to the elastic-plastic model, the fragility coefficient of rock $\beta=0$, $k_{p 1}=k_{p 2}=k_{p}$. Without the influence of thermal stress, the radius of plastic zone can be simplified from Eq. (23) as follows:
$R_{p}=r_{w}\left(\frac{\frac{2}{k_{p}+1}\left(\sigma_{\mathrm{o}}+\frac{\sigma_{c e}}{k_{p}-1}\right)}{p_{i}+\frac{\sigma_{c e}}{k_{p}+1}}\right)^{\frac{1}{k_{p}-1}}$

Equation (27) is the formula that Kastner proposed to calculate the radius of the plastic zone under the ideal elastic-plastic model (Kastner 1971).

2. The radius of plastic zone with the ideal elastic-brittle model

When the surrounding rock conforms to elasticbrittle model, the fragility coefficient of rock is $\beta \rightarrow \infty$, $k_{p 1}=k_{p 2}=k_{p}$. The limit of Eq. (15) can be calculated as $\lambda \rightarrow 1$. Without the influence of thermal stress, the limit analysis for both ends of Eq. (23) can obtain the radius of plastic zone:

$R_{p}=r_{w}\left(\frac{\frac{2 \sigma_{0}}{k_{p}+1}+\frac{\sigma_{c s}}{k_{p}-1}-\frac{\sigma_{\mathrm{ce}}}{k_{p}+1}}{p_{i}+\frac{\sigma_{\mathrm{cs}}}{k_{p}+1}}\right)^{\frac{1}{k_{p}-1}}$
Fig. 3 Measured radius of borehole and radius of bit in the gas drilling section

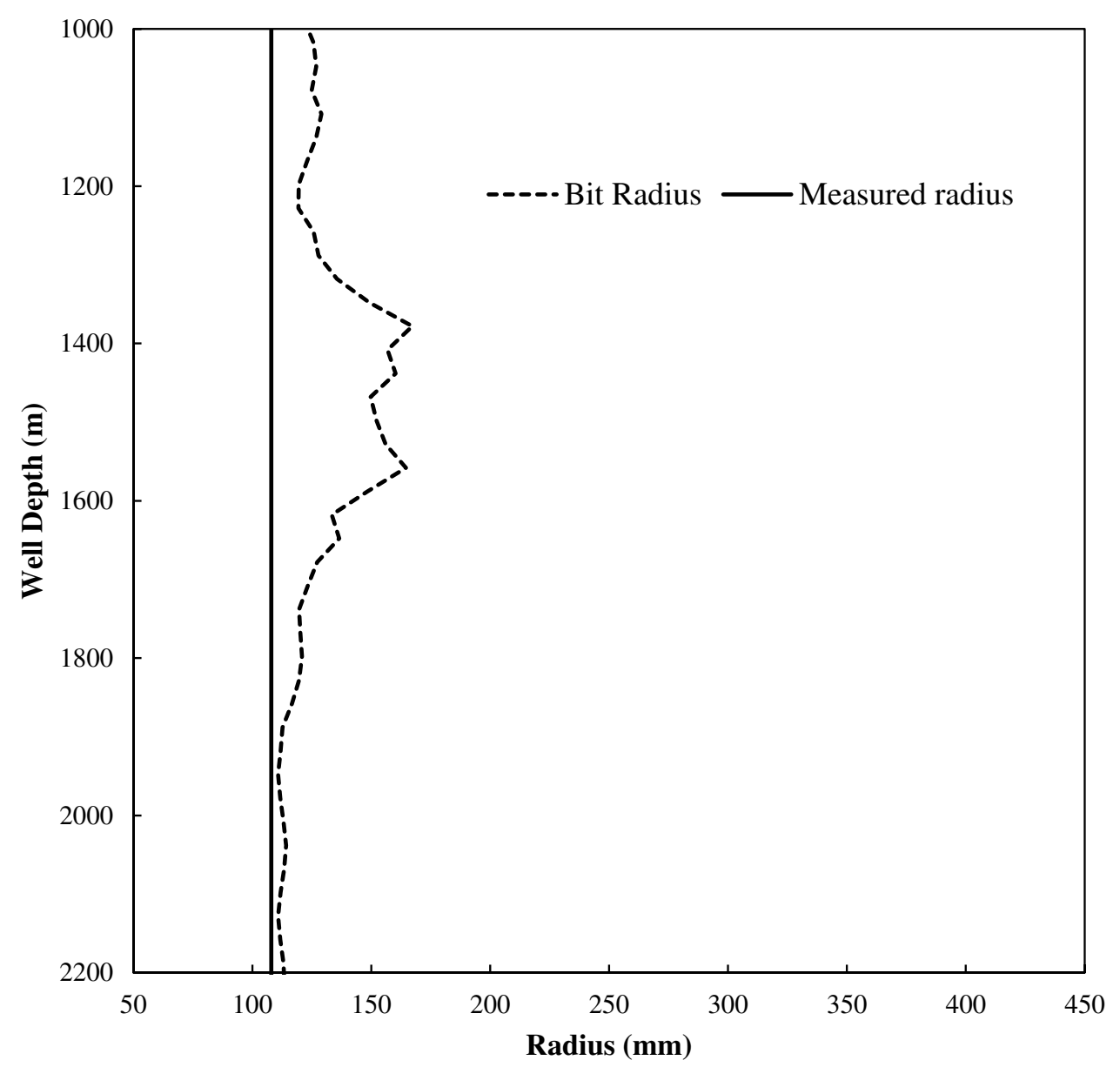


Equation (28) is the formula that Airy proposed to calculate the radius of plastic zone under the ideal elastic-plastic model (Yu et al. 1983).

Therefore, Kaster and Airy models for the radius of plastic zone can be obtained by simplifying the ideal elastic-plastic softening model proposed in the paper. The ideal elastic-plastic softening model has good universality.

\section{Model validation}

During gas drilling, the stability of the rock around borehole can be estimated by comparing the measured borehole radius with the plastic radius calculated by the model. The accuracy of the model can be verified indirectly if the variation trend of the plastic radius of surrounding rock is close to the measured borehole radius.

As an example, the data of the well HB021 in Xinjiang oilfield is used for validating the model. The gas drilling section of the well HB021 is the depth of 1000-2200 m, and the well radius curve is shown in Fig. 3 which shows that the radius of the well Sect. $1300-1600 \mathrm{~m}$ is seriously enlarged because the borehole wall collapse is severe. The borehole radius at the depth of $1000-1300 \mathrm{~m}$ is larger than other sections.

The construction and thermodynamic parameters of the well HB021 are listed in Table 1.

The pressure and temperature distributions in the borehole calculated from the borehole flow and heat transfer model are shown in Figs. 4 and 5.

Figure 4 shows that the gas flow pressure in the annulus was very low during gas drilling, and the pressure in the upper well section was within 1.0 MPa. Figure 5 demonstrates that the gas temperature in the annulus during gas drilling decreased by $17.5{ }^{\circ} \mathrm{C}$ than the original formation temperature near the bottom borehole because the Joule-Thomson effect occurred at the bit nozzle. As the gas flows upward, it was heated gradually by the formation, and the temperature rises gradually. When the depth decreased to around $1600 \mathrm{~m}$, the temperature was equal to the formation temperature, and then the gas temperature in the annulus was slightly higher than the formation temperature for it flowing upward to wellhead. This means that in gas drilling, the rock of the borehole wall experienced a cooling process, and then gradually reached to the original formation temperature, finally becoming slightly higher than the original formation temperature.
Table 1 Construction parameters and thermodynamic parameters of the well HB021

\begin{tabular}{|c|c|}
\hline Parameters & Value \\
\hline Upper hole diameter, mm & 311.2 \\
\hline Casing O.D, mm & 244.5 \\
\hline Casing-wall thickness, $\mathrm{mm}$ & 8.94 \\
\hline Casing setting depth, $\mathrm{m}$ & 1000 \\
\hline Pipe O.D, mm & 127 \\
\hline Pipe I.D, mm & 108.6 \\
\hline Collar O.D, mm & 158.25 \\
\hline Collar I.D, mm & 71.44 \\
\hline Collar Length, $\mathrm{m}$ & 300 \\
\hline Bit diameter, mm & 215.9 \\
\hline Nozzle diameter, mm & 21 \\
\hline Number of nozzles & 3 \\
\hline Thermal conductivity of drillstrings and casing, W/m ${ }^{\circ} \mathrm{C}$ & 23.26 \\
\hline Thermal conductivity of cement ring, $\mathrm{W} / \mathrm{m}{ }^{\circ} \mathrm{C}$ & 0.52 \\
\hline Formation thermal diffusion coefficient, $\mathrm{m}^{2} / \mathrm{s}$ & 1.03 \\
\hline Formation thermal conductivity, $\mathrm{W} / \mathrm{m} .{ }^{\circ} \mathrm{C}$ & 2.06 \\
\hline Thermal expansion coefficient of formation, $10^{-5} /{ }^{\circ} \mathrm{C}$ & 2.36 \\
\hline Density of rock, $\mathrm{kg} / \mathrm{m}^{3}$ & 2540 \\
\hline Young's modulus of rock, GPa & 40 \\
\hline Rock Poisson's ratio & 0.2 \\
\hline Rock cohesion, $\mathrm{MPa}$ & 14.08 \\
\hline Internal friction angle of rock, degree & 18.8 \\
\hline Brittleness coefficient of rock & 1.0 \\
\hline Maximum horizontal geostress, $\mathrm{MPa} / 100 \mathrm{~m}$ & 2.23 \\
\hline Minimum horizontal geostress, $\mathrm{MPa} / 100 \mathrm{~m}$ & 1.82 \\
\hline Overburden pressure, $\mathrm{MPa} / 100 \mathrm{~m}$ & 2.24 \\
\hline Effective geostress coefficient & 0.4 \\
\hline Geothermal gradient, ${ }^{\circ} \mathrm{C} / \mathrm{m}$ & 0.0226 \\
\hline Ground temperature, ${ }^{\circ} \mathrm{C}$ & 25 \\
\hline Outlet pressure, $\mathrm{MPa}$ & 0.1 \\
\hline Gas injection pressure, $\mathrm{MPa}$ & $2.0-4.0$ \\
\hline Gas injection temperature, ${ }^{\circ} \mathrm{C}$ & 38 \\
\hline Gas injection rate, $\mathrm{m}^{3} / \mathrm{min}$ & $150-180$ \\
\hline Penetration rate, $\mathrm{m} / \mathrm{hr}$ & 6.4 \\
\hline
\end{tabular}

According to the borehole pressure and temperature parameters in Figs. 4 and 5, the plastic and broken radius of the borehole deformation in presence or absence of thermal stress is demonstrated in Fig. 6.

In Fig. 6, the plastic radius of the borehole obtained from the complete strain-stress model accompanied by thermal stress during gas drilling has a high consistency with the ones in Fig. 3. On the contrary, the radius of 
Fig. 4 Pressure distribution in the gas drilling section

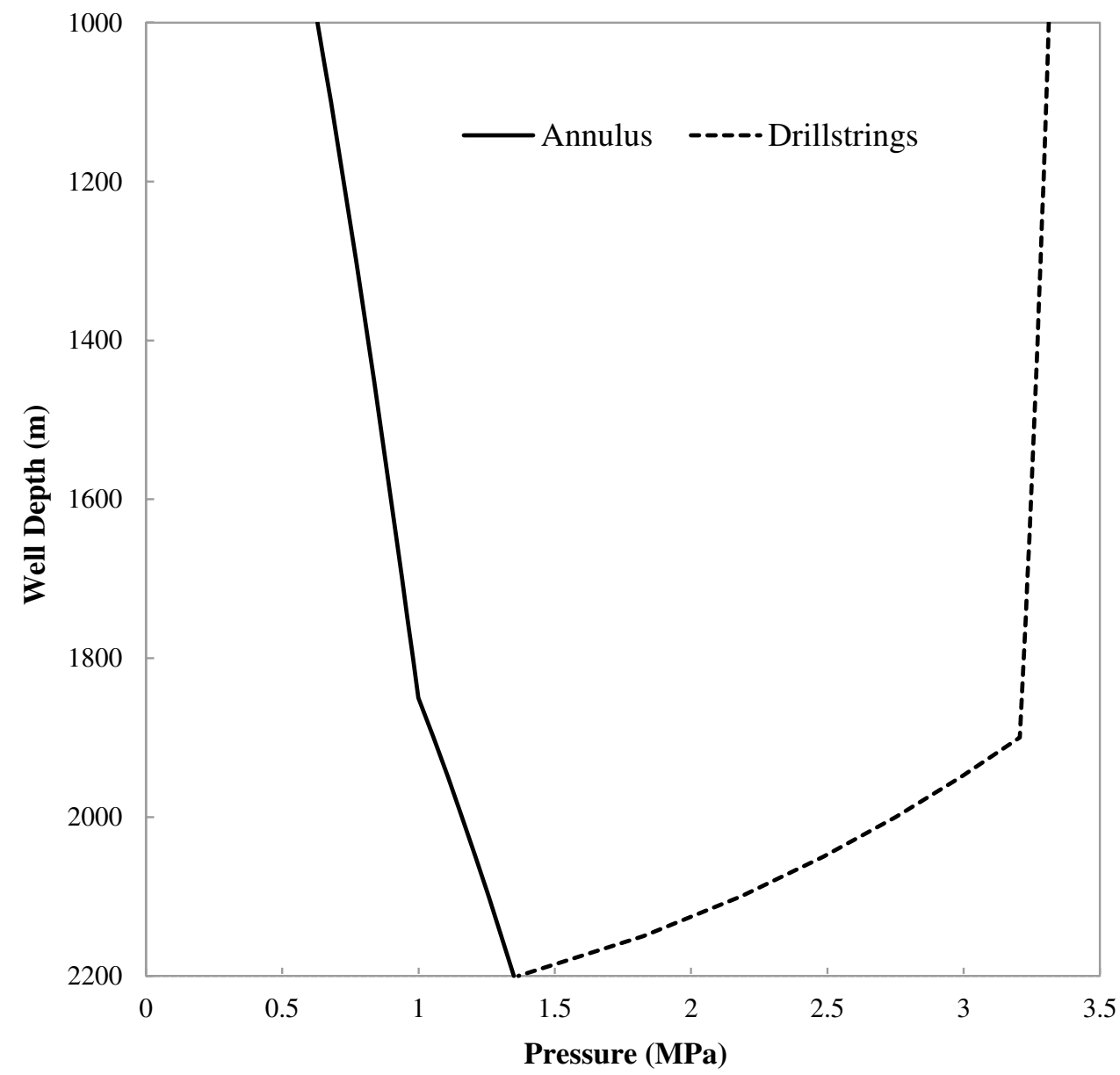

the plastic zone of surrounding rock without thermal stress shows that it is smaller at the top and larger at the bottom, and the radii of the plastic and residual zones increases rapidly in the depth of $1500 \mathrm{~m}$ through $2200 \mathrm{~m}$. The results obtained from the complete strain-stress model without thermal stress are not consistent with the actual radius of borehole in Fig. 3. Therefore, the complete strain-stress model accompanied by thermal stress is verified availability to gas drilling.

\section{Results and discussion}

Comparison between Figs. 6 and 5 shows that the plastic radius without considering thermal stress is much higher than the one with thermal stress near the bottom borehole. The borehole temperature is far lower than the original geothermal value in Fig. 5. Thermal stress results from temperature differences before and after drilling into the formation shrinks the rocks and counteracted the expansion of rock due to the in situ stress. In the upper part of the borehole, the rock expanded by the thermal stress because the borehole temperature is higher than the formation temperature. The expanded rock aggravates the expansion of rock under the original in situ stress of the borehole. Therefore, thermal stress at the bottom of the borehole enhances the stability of the borehole, while thermal stress at the upper part of the borehole aggravates the instability of the borehole.

When the rock of the borehole wall is in the elastic stage, its stability is very strong. However, if the rock is in the plastic stage, it is in the transition stage from stability to instability. If rock of the borehole wall is in the residual area, it comes to the unstable stage. The gas flow pressure in the borehole is usually less than $3 \mathrm{MPa}$ during gas drilling. It is too weak to support the borehole 
Fig. 5 Temperature distribution in the gas drilling section

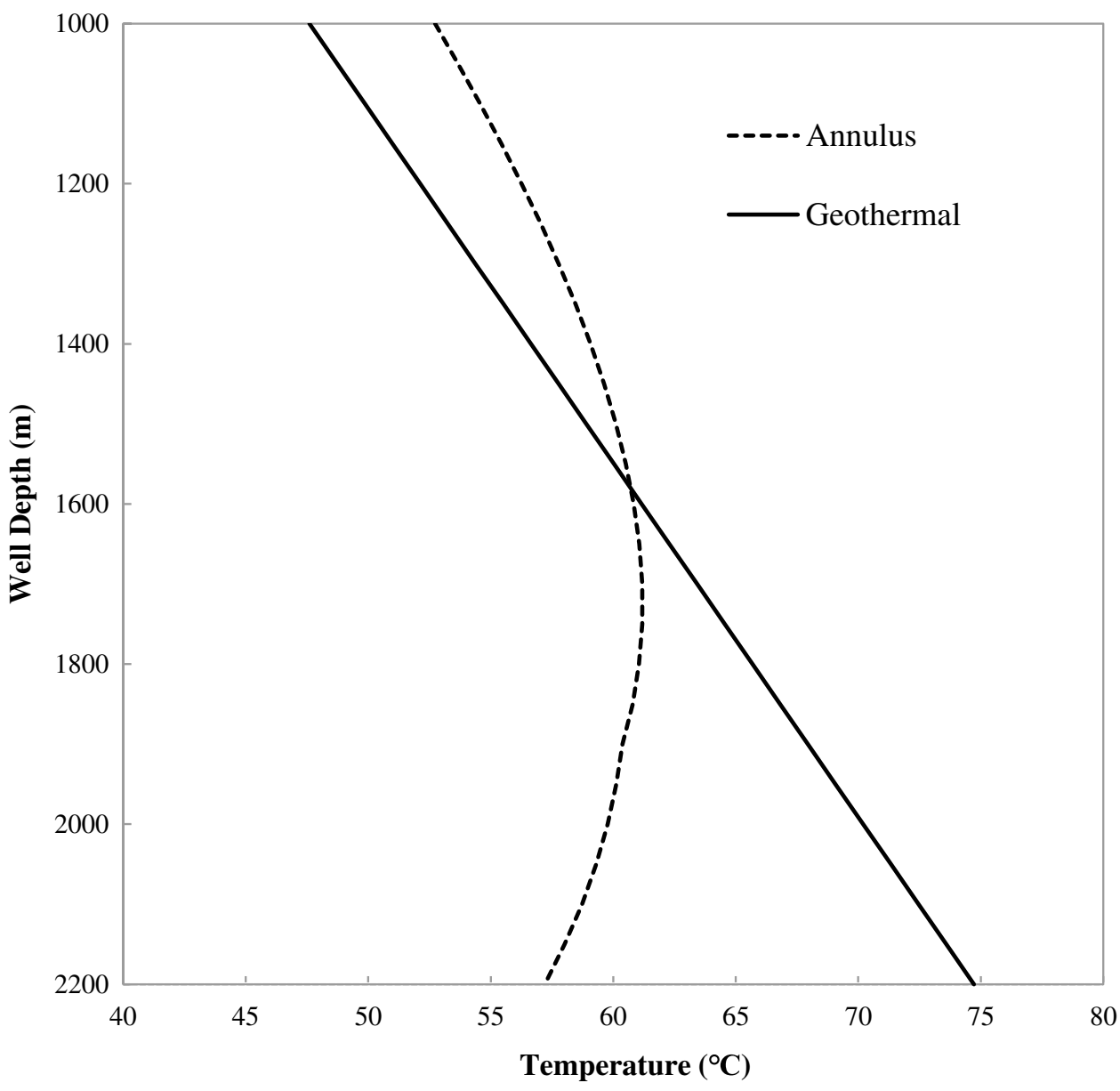

wall. In addition, the high velocity in gas drilling washed the well wall more severely than mud drilling, so the radius of the borehole expanded further, and ultimately, the rock in the borehole wall reached a stable state.

In order to compare with the conventional borehole stability evaluation method of mud drilling, the borehole deformation is given in the form of collapse pressure. The collapse pressure distributions of borehole wall is calculated for the different penetrated depth of $1300 \mathrm{~m}, 1600 \mathrm{~m}$, $2000 \mathrm{~m}$, and $2200 \mathrm{~m}$ still base on the data of the well HB021. The results are shown in Fig. 7.

Figure 7 shows that the collapse pressure of borehole wall is changing and presents a trend of gradually increasing with the increase of gas drilling depth. The collapse pressure at about $1400 \mathrm{~m}$ was positive at $2200 \mathrm{~m}$. The borehole wall is unstable due to the weak gas support ability. It is worth noting that the collapse pressure method can also describe the wellbore stability of gas drilling, but it is not intuitive to use the plastic radius and broken radius method.

\section{Conclusions}

1. The borehole instability mechanism of gas drilling is different from that of mud drilling. In gas drilling, the borehole wall rock still has a certain bearing capacity after reaching peak strength. The deformation of rock around borehole can be divided into elastic zone, plastic zone, and fracture zone using complete stress-strain model, which is more consistent with the stress-strain process of borehole wall rock.

2. Introducing the thermal stress into the complete stress-strain evaluation model of the borehole wall stability, the comparison of calculating the radii of plastic zone and broken zone of surrounding rock of borehole with measured caliper, the results show that the established model can better explain the gas drilling borehole wall instability mechanism, the radius of plastic zone and broken zone characterization of gas drilling borehole wall stability more intuitive. 
Fig. 6 Borehole deformation in presence and absence of thermal stress

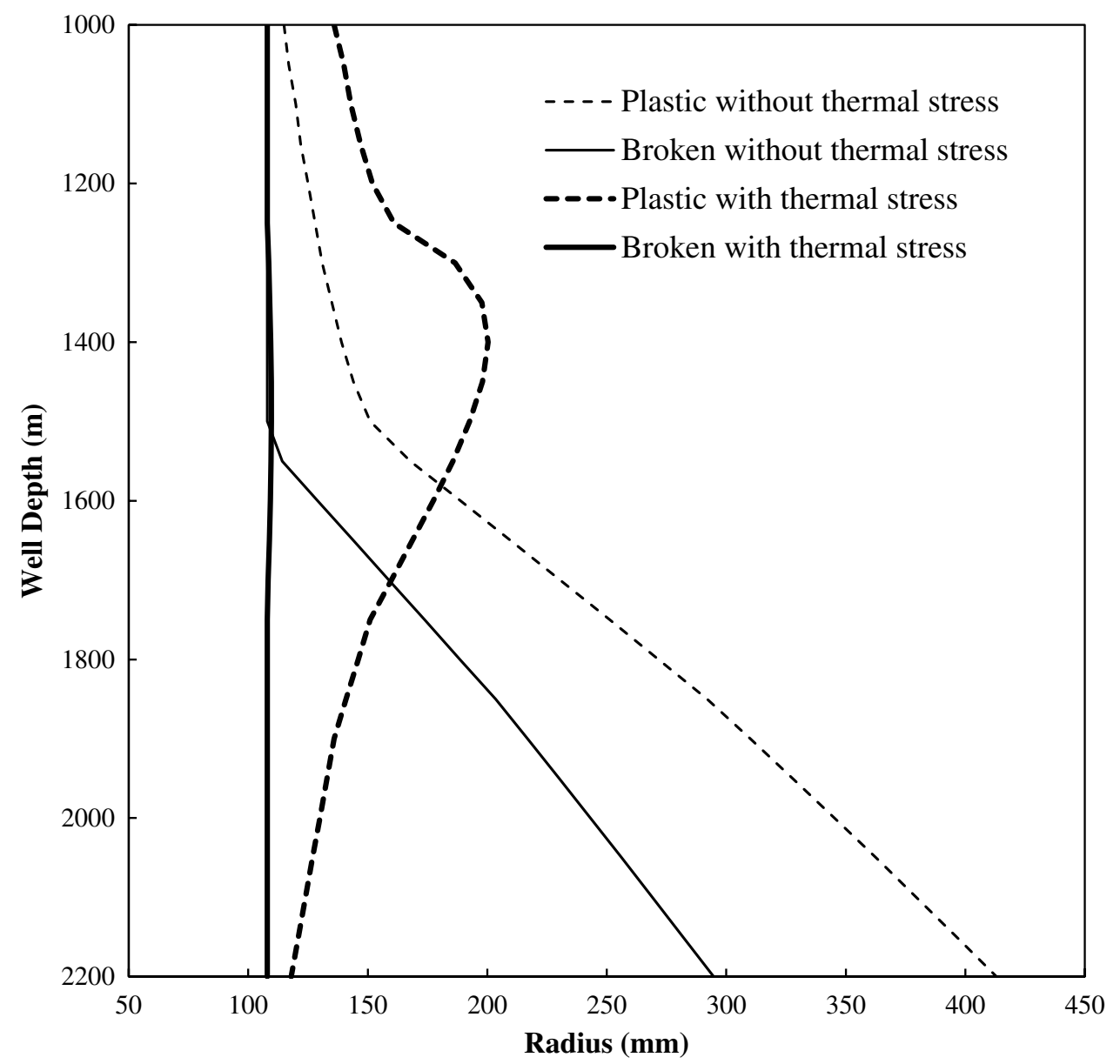

3. In the gas drilling process, the borehole temperature is much lower than the original formation temperature near the bottom of the hole, and in the upper part of the borehole, the borehole temperature is higher than the formation temperature. Thermal stress has a significant effect on borehole stability. The thermal stress in the bottom borehole makes the rock shrink and offset the expansion of the original in situ stress on the surrounding rock, thus enhancing the stability of the borehole wall. The surrounding rock in the top borehole expands under the action of thermal stress, enhancing the expansion of the surrounding rock toward the borehole and aggravating the instability of the borehole wall. 
Fig. 7 Collapse pressure distributions of the different penetrated depth

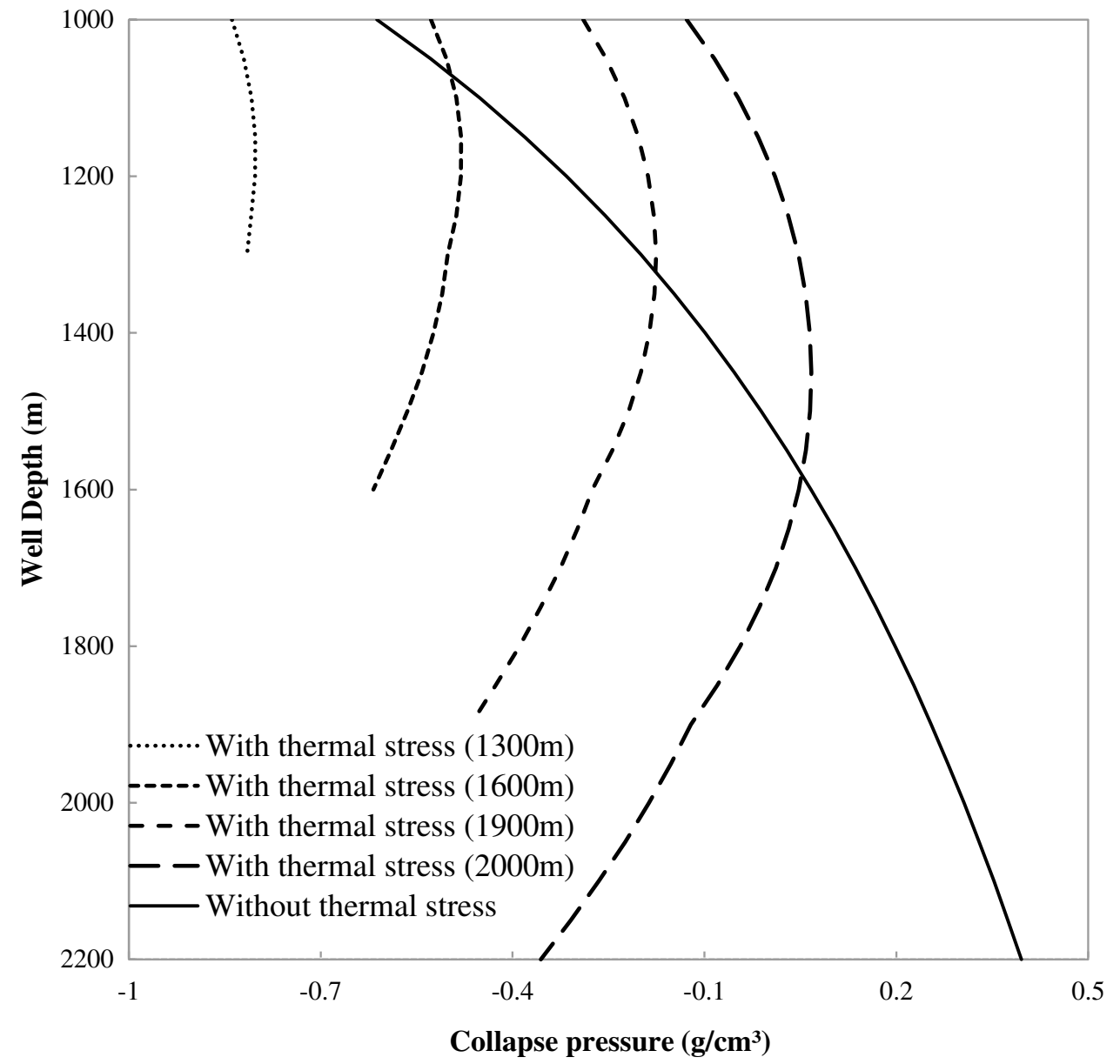

Nomenclature $E$ : The elastic modulus of elastic deformation, MPa; $E_{p}$ : The softening modulus of plastic softening deformation, MPa; $M$ : The plastic deformation modulus, MPa; $\beta$ : The fragility coefficient; $\sigma_{\theta}, \sigma_{r}$ : The tangential and radial stresses, MPa; $\sigma_{c e}$ : The uniaxial compressive strength in the process of elastic deformation, $\mathrm{MPa} ; \varphi_{e}$ : The angle of internal friction of elastic deformation, degree; $\sigma_{c p}$ : The uniaxial compressive strength of the plastic deformation, MPa; $\varphi_{p}$ : The angle of internal friction of plastic deformation degree; $\sigma_{c s}$ : The uniaxial compressive strength of the residual deformation, MPa; $\sigma_{o}$ : The gradual increase of the average horizontal goestress, MPa; $R_{p}$ : The radius of the plastic zone, $\mathrm{m} ; \sigma_{r e}$ : The radial stress at the interface of the elastic-plastic zone, MPa; $\nu$ : Rock Poisson's ratio; $R_{s}$ : The radius of the broken zone, $\mathrm{m} ; \lambda$ : The radius ratio of the broken zone to the plastic zone, $\lambda=R_{s} / R_{p} ; \rho_{g}, \rho_{f}$ : The density of gas and rock, $\mathrm{kg} / \mathrm{m}^{3} ; V_{p}$, $V_{A}$ : The gas velocity in drillstrings and annulus, $\mathrm{m} / \mathrm{s} ; A_{p}, A_{A}$ : The crosssection of drillstrings and annular, $\mathrm{m}^{2} ; c_{p g}, c_{p f}$ : The specific heat of gas and rock, $\mathrm{J} / \mathrm{kg} .{ }^{\circ} \mathrm{C} ; T_{p}, T_{A}, T_{w}$ : The temperature of gas in drillstrings, gas in annulus and rock in the borehole wall, ${ }^{\circ} \mathrm{C} ; U_{t}$ : The total heat transfer coefficient between the drillstrings and the rock in the borehole wall, $\mathrm{J} / \mathrm{s}{ }^{\circ} \mathrm{C} \mathrm{m} ; h_{t}$ : The heat transfer coefficient of rock in borehole wall, $\mathrm{J} / \mathrm{s}{ }^{\circ} \mathrm{C} \mathrm{m} ; k_{f}$ : The formation thermal conductivity, $\mathrm{J} / \mathrm{h}{ }^{\circ} \mathrm{C} \mathrm{m} ; r, r_{p}$, $r_{w}$ : The radial coordinates, drillstrings radius and borehole radius, $\mathrm{m}$; $t$ : Time, $\mathrm{s} ; z$ : The well depth, $\mathrm{m} ;{\sigma_{r}^{T}}^{T}, \sigma_{\theta}^{T}$ : The thermal stresses in the radial, tangential, and axial directions caused by formation temperature changes, $\mathrm{MPa} ; \alpha$ : The thermal expansion coefficient of the formation, $1 /{ }^{\circ} \mathrm{C} ; T_{w}$ : The gas temperature at the borehole wall, ${ }^{\circ} \mathrm{C} ; T_{0}$ : The initial formation temperature, ${ }^{\circ} \mathrm{C} ; R_{p c}$ : The plastic zone radius of the critical state, $\mathrm{m} ; p_{i}$ : The borehole gas pressure, $\mathrm{MPa}$

Funding This work was financially supported by the National Natural Science Foundation of China (Contract No. 51474036) and the Outstanding Young and Middle-aged Science and Technology Innovation Team Project of Hubei Provincial Colleges and Universities (Contract No. T201804).

\section{Declarations}

Conflict of interest The authors declare no competing interests.

Open Access This article is licensed under a Creative Commons Attribution 4.0 International License, which permits use, sharing, adaptation, distribution and reproduction in any medium or format, as long as you give appropriate credit to the original author(s) and the source, provide a link to the Creative Commons licence, and indicate if changes were made. The images or other third party material in this article are included in the article's Creative Commons licence, unless indicated otherwise in a credit line to the material. If material is not included in the article's Creative Commons licence and your intended use is not permitted by statutory regulation or exceeds the permitted use, you will need to obtain permission directly from the copyright holder. To view a copy of this licence, visit http://creativecommons.org/licenses/by/4.0/. 


\section{References}

Akong B, Dosunmu A, Lonna U et al (2011) Geomechanical modeling of thermal effects on wellbore stability using the thermo- poroelastic model in HPHT wellbores. SPE150771. https://doi.org/ 10.2118/150771-MS

Al-Ajmi AM, Zimme RW (2005) Stability analysis of deviated boreholes using the Mogi-Coulomb failure criterion, with applications to some North Sea and Indonesian Reservoirs. Int J Rock Mech Min Sci 42(3):431-439

Al-Ajmi AM, Zimme RW (2006) Stability analysis of vertical boreholes using the Mogi-Coulomb failure criterion. Int J Rock Mech Min Sci 43(8):1200-1211

Chen J, Feng X (2007) Study on constitutive model for hard rock under high geostresses. Rock Soil Mech 28(11):2271-2278. https://doi. org/10.16285/j.rsm.2007.11.011

Chen J, Yuan W (1988) Elastio-plastic and limit state analyses of underground rock structure. Eng Mech 5(1):117-126

Ding S, Jiang H, Xi Y et al (2018) The micro mechanical cause and pore selection mechanism of remaining oil at ultra-high water cut period. J Liaoning Shihua Univ 38(1):45-49

Fang D, Wang H (1991) Stress analysis of underground tunnel with consideration of brittle-plastic transition behavior of the rock. Underground Space 11(1):15-23

Griston S, Willhite GP (1987) Numerical model for evaluating concentric steam injection wells. SPE16337. https://doi.org/10.2118/ 16337-MS

Guo B, Li G, Song J (2016) An analytical thermal-model for optimization of gas-drilling in unconventional tight-sand reservoirs. J Sustain Energy Eng 4(2):108-126. https://doi.org/10.7569/jsee. 2016.629516

Guo B, Ghalambor A (2002) An innovation designing underbalanced drilling flow rates: a gas-liquid rate window (GLRW) approach. SPE77237. https://doi.org/10.2118/77237-MS

Guo T, Tang S, Liu S et al (2021) Physical simulation of hydraulic fracturing of large-sized tight sandstone outcrops. SPE J, Feburary: 372-393

Hasan AR, Kabir CS, Ameen MM (1996a) A fluid circulating temperature model for workover operations. SPE J 1(02):133-144. https:// doi.org/10.2118/27848-pa

Hasan AR, Kabir CS, Ameen MM et al (1996) A mechanistic model for circulating fluid temperature. SPE27848. https://doi.org/10. 2118/27848-PA

Huang J, Cui M, Luo P (1995) Study on wellbore stability in misted air drilling. Drill Complet Fluids 12(5):6-10

Jiang Z, Zhang J, Meng Y et al (2007) Analysis on the methods used to evaluate the wellbore stability of gas drilling. Nat Gas Ind 27(11):68-70

Kabir CS, Hasan AR, Kouba GE et al (1996) Determining circulating fluid temperature in drilling, workover, and well control operationS. SPE Drill Complet 11(02):74-79. https://doi.org/10.2118/ 24581-pa

Kastner H (1971) Kavernen. In: Statik des Tunnel- und Stollenbaues. Springer, Berlin, Heidelberg. https://doi.org/10.1007/978-3-66236311-9_10
Keller HH, Couch EJ, Berry PM (1973) Temperature distribution in circulating mud columns. Soc Petrol Eng J 13(01):23-30. https:// doi.org/10.2118/3605-pa

Lee T (1982) Estimation of formation temperature and thermal property from dissipation of heat generated by drilling. Geophysics 47(11):1577-1584. https://doi.org/10.1190/1.1441308

Li A (1994) Primary study of the stability of air drill hole. West-China Explor Eng 6(1):11-14

Li J, Guo B, Li B (2015) A closed form mathematical model for predicting gas temperature in gas-drilling unconventional tight reservoirs. J Nat Gas Sci Eng 27:284-289. https://doi.org/10.1016/j. jngse.2015.08.064

Li Y, Jia D, Rui Z et al (2017) Evaluation method of rock brittleness based on statistical constitutive relations for rock damage. J Petrol Sci Eng 153:123-132

Liu H, Meng Y, Wan S, Li G et al (2010) Analysis of wellbore stability during gas drilling through high-pressure gas formations. Nat Gas Ind 30(11):59-62. https://doi.org/10.3787/j.issn.1000-0976. 2010.11 .016

Lu D, Du X (2013) Research on nonlinear strength and failure criterion of rock material. Chin J Rock Mech Eng 32(12):2394-2408

Nguyen DA, Miska SZ, Yu M et al (2010) A. modeling thermal effects on wellbore stability SPE133428. https://doi.org/10.2118/ 133428-MS

Nie Z, Xia B, Zhou L et al (2011) Modeling of wellbore stability for gas drilling. Nat Gas Ind 31(6):71-76. https://doi.org/10.3787/j. issn.1000-0976.2011.06.015

Ramey HJ (1962) Borehole heat transmission. J Petrol Technol 14(4):427-435

Wilson H (1980) A method of estimating the closure and strength of lining required in drivages surrounded by a yield zone. Int J Rock Mech Min Sci Geomech Abstr 17(6):349-355

Wu Y, Lin Z (1987) Experimental study of the post-failur behaviours of rock under uniaxial compressive loading. Yantu Gongcheng Xue Bao 9(1):23-31

Yang X, Shi X, Meng Y et al (2019) Wellbore stability analysis of layered shale based on the modified Mogi-Coulomb criterion. Petroleum. https://doi.org/10.1016/j.petlm.2019.11.002

Yang E, Fang Y, Liu Y et al (2020) Research and application of microfoam selective water plugging agent in shallow low -temperature reservoirs. J Petrol Sci Eng 193:107354. https://doi.org/10.1016/j. petrol.2020.107354

Yu X, Zheng Y, Liu H et al (1983) Wall rock stability analysis of underground engineering. Coal Industry Press, Beijing

Yuan W, Chen J (1986) Analysis of plastic zone and loose zone around opening in softening rockmass. J China Coal Soc 9(3):77-86

Zhang H, Zhang H, Guo B et al (2012) Analytical and numerical modeling reveals the mechanism of rock failure in gas UBD. J Nat Gas Sci Eng 4(none):29-34. https://doi.org/10.1016/j.jngse.2011. 09.002

Zhou X, Qian Q, Yang H (2008) Strength criteria of deep rock mass. Chin J Rock Mech Eng 27(1):118-123. https://doi.org/10.3321/j. issn.1000-6915.2008.01.018 